\title{
LETTER FROM THE PRESIDENT
}

\section{C

Happy New Year, NACIS:

My first NACIS conference was in 1998 in Milwaukee, WI, where I gave a presentation on my dissertation. A few years later I was asked to run for the NACIS Board of Directors. Next, I took over organizing the student poster competition, served on the Board a few more times, became Editor of Cartographic Perspectives, and am now writing to you as the President of NACIS. Serving the organization in these different capacities has allowed me to give back to the Society that has been an enjoyable home to me for the past 20 years. NACIS remains a vibrant community of like-minded individuals who share a passion for all things map related. I am honored to serve as your President and hope to propel NACIS forward into 2018 and beyond.

At the close of every year, people tend to reflect and acknowledge significant achievements. The popularity of the NACIS Annual Meeting continues to grow, and Montréal 2017 was no exception, with over 350 attending. Considering that the conference was outside the United States, making international travel difficult for some, conference participation was incredibly strong. Practical Cartography Day continues to be a well-attended event with nearly 200 participants, even requiring several last-minute adjustments to the rooms in order to accommodate everyone. The paper presentations included a diverse cross-section of topics, which is a driving force in making the main conference rewarding and memorable. Geoffrey Mandel gave a fascinating keynote on his cartographic work with Star Trek and other science fiction productions.

In 2016, in Colorado Springs, CO, NACIS experimented with video recording and live streaming Practical Cartography Day. Given the success of this venture, NACIS wanted to expand on this initiative,

\section{VIDEO: GEOFFREY MANDEL'S KEYNOTE}

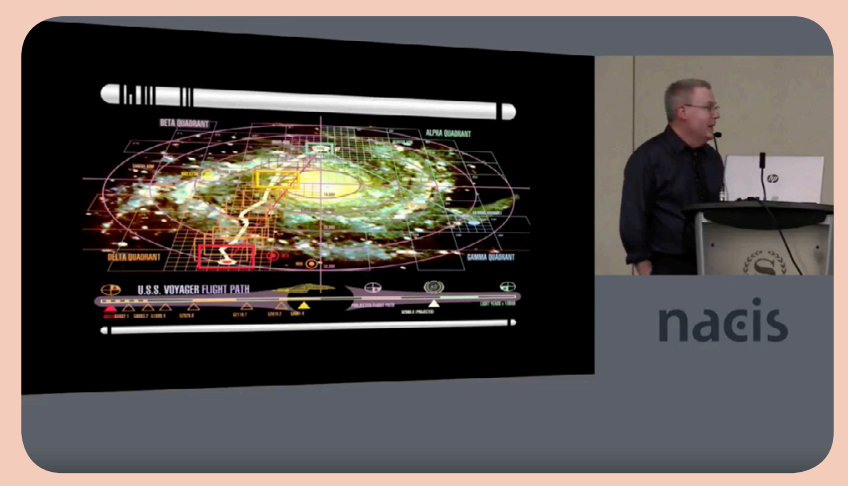

Click to watch, or visit youtu.be/Ex0Rc0Qz0wo. so in Montréal 2017, 
recording and live streaming were available for all session tracks. As a member benefit, the NACIS community throughout the world was able to virtually participate. For conference attendees, live streaming offered a unique option to participate while sitting in the hotel commons, another parallel session, a hotel room, or a coffee shop down the street. Based on the post-conference survey, there was unanimous support for video recording and streaming. However, despite this success, video recording and live streaming incurs a significant expense and will not be sustainable for future conferences without our securing sponsored funding. The NACIS Board is looking into possible funding solutions and we encourage anyone from the NACIS community to suggest creative ways to keep video recording and live streaming ongoing as we look forward to Norfolk, VA and beyond. Check out the video recordings of the conference: http://bit.ly/2yOpxTb.

There have been a few personnel changes at NACIS to report. Tanya Buckingham stepped down from her role as Executive Director at the end of 2017. Tanya has diligently and selflessly served NACIS in many roles including those of President and Secretary. The NACIS community is sad to see her depart and thanks Tanya for her dedicated service to the Society not only in her current role but also in the diverse duties she has taken on during her many years as a leader in the organization. It is, however, with great excitement that I report that Tom Patterson, another long-time and involved NACIS member, has stepped forward to fill this position! Tom brings with him a strong record of contributions to the Society and a tremendous level of institutional knowledge. We welcome Tom to the Executive Director's position and we look forward to working with him to help lead NACIS into the future.

There are three NACIS initiatives on which I would like to report. First, it is hard to imagine but preparations for Volume \#4 of the Atlas of Design are now underway. The success of the Atlas of Design has been tremendous and I extend my thanks to the current editors Alethea Steingisser, Lauren Tierney, and Caroline Rose for the excellent work they have done with this project. The Atlas of Design continues to be a popular outlet for the exhibition of stunning cartography. For more information on how you can contribute to this effort please visit atlasofdesign.org.

Second, Editor Amy Griffin continues to advance Cartographic Perspectives $(C P)$ as the only freely available, peer-reviewed open access cartography journal in the world. $C P$ offers a diverse set of content, including Practical Cartographer's Corner, presenting tips of the cartographic trade, Cartographic Collections, offering insights into map collections, Visual Fields, displaying beautiful cartographic works, and the ever popular Book Reviewws, providing perspectives on recent cartographic literature. For authors interested in publishing their research in $C P$, reviews are quick, content is published in full color at no cost to the authors, and accepted and copyedited submissions are posted as open access. So, please consider $C P$ as an outlet for your cartographic publications and take some time to look through the many diverse contributions in this issue of $C P$.

Third, during our 2017 Spring Board Meeting, the NACIS Board of Directors made the decision to wind down our support of CartoTalk, our online cartography discussion forum. Activity has been declining over the years, and, given our limited pool of volunteer time, it no longer makes sense for us to continue to maintain it. The Board is willing to turn over control of CartoTalk to another party that is interested in investing the energy needed to revitalize it, and willing to maintain it as a broad community that is not focused on one 
particular technology or variety of mapmaking. We will keep the membership updated on CartoTalk.

Looking forward to 2018, Vice President Ginny Mason, VP-Elect Leo Dillon, and Business Manager Susan Peschel are diligently organizing the next Annual Meeting, in Norfolk, VA. Please check out nacis.org/2018 for updated information; we would really like to see you there! If you have ideas on how to contribute to the conference please let one of the organizers know as we strive to make the conference as beneficial as possible to the NACIS community.

I will close with a nod to the fact that NACIS is a community of volunteers who freely donate their time and efforts for the betterment of the Society. Volunteers serve on the NACIS Board, work on initiatives like the Atlas of Design, and help in countless other ways to make the annual conference a success. Thank you to all of the volunteers who donated their time and efforts in 2017 to making NACIS the Society it is. If you are interested in lending your time and talents to help the Society continue into 2018 and beyond please reach out to me or anyone on the NACIS Board. We would be much obliged for new perspectives, new voices, and new talents.

I hope that everyone had a successful 2017 and that 2018 will be equally gainful.

\section{Fritz Kessler}

President, NACIS 